$\mathrm{DE}$

M E D I C I N A

T R O P I C A L

$\mathrm{DE}$

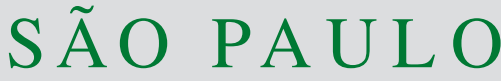

JOURNAL OF THE SÃO PAULO INSTITUTE OF TROPICAL MEDICINE

Universidade Federal do Estado do Rio de Janeiro, Hospital Universitário Gaffrée e Guinle, Centro de Ciências Biológicas e da Saúde, Rio de Janeiro, Rio de Janeiro, Brazil

Correspondence to: Walter de Araujo Eyer-Silva

Universidade Federal do Estado do Rio de Janeiro, Hospital Universitário Gaffrée e Guinle, Departamento de Medicina Geral, Centro de Ciências Biológicas e da Saúde, $10^{\text {a }}$ enfermaria, Rua Mariz e Barros, 775 , CEP 20270-004, Tijuca, Rio de Janeiro, RJ, Brazil

Tel: +55 21 99953-7051

E-mail: walter.eyer@ig.com.br

Received: 3 July 2017

Accepted: 22 August 2017

\section{Secondary syphilis presenting as leucoderma syphiliticum: case report and review}

\author{
Walter de Araujo Eyer-Silva, Carlos José Martins, Guilherme Almeida Rosa \\ da Silva, Giresse Acakpovi, Jorge Francisco da Cunha Pinto
}

KEYWORDS: HIV infection. Leucoderma syphiliticum. Syphilis.

\title{
INTRODUCTION
}

Acquired syphilis is a sexually transmitted infection caused by the spirochete Treponema pallidum, subspecies pallidum. It has a triphasic natural history in which a secondary stage of florid mucocutaneous manifestations follows a primary ulcer (chancre) and is preceeded by a tertiary stage of slowly progressive, destructive inflammatory processes that can affect any organ. Due to its heterogeneity of presentation and mimicry of other conditions, syphilis has been aptly described as "the great imitator".

The clinical presentation of secondary syphilis is so polymorphic that it should be included in the differential diagnosis of virtually any skin rash of unknown etiology. Current and older literature provide a very wide spectrum of unusual presentations of syphilis. A well-recognized, but rarely reported manifestation of secondary syphilis is leucoderma syphiliticum (LS), a condition first described as syphilide pigmentaire by Alfred Hardy in $1854^{1}$ and later studied by several authors. The term LS was first proposed in 1883 by Neisser ${ }^{2-4}$. The older literature remarked that this unusual condition was most commonly observed in young female patients and emerged about the time or several months (occasionally much later) after the disappearance of the typical syphilitic rash ${ }^{1,3,5-8}$. Therefore, it was considered a late expression of secondary syphilis. The dyschromia could be so faint that could require a strong light and a certain positioning for detection, and could easily be confused with areas of dirty skin ${ }^{6,9}$. As pointed out by Fournier, the cervical region was almost exclusively affected in "twenty-nine out of thirty cases" ${ }^{\text {. }}$. The term 
necklace of Venus, or venereal necklace was then coined to describe this peculiar topographic preference ${ }^{6}$. The condition was not linked to any particularly severe form of syphilis. Instead, it was observed during the course of moderate or benign forms of the disease ${ }^{6}$.

Very few case reports of LS are available on modern biomedical databases. We reported on the case of an HIVinfected male patient in whom a clinical diagnosis of LS was made. A review on syphilis-related pigmentary changes will follow.

\section{CASE REPORT}

A 57-year-old male patient who had been diagnosed with HIV infection 23 years previously presented with a mildly burning and pruritic hypochromic rash of three-months duration. The first lesions emerged on shoulders and proximal arms, but soon progressed to the chest, abdomen, flanks, and dorsum. He informed that, when the illness was first noticed, the lesions were mildly erythematous, but he could not recall if the palms and soles were also affected. Sun exposure seemed to worsen the overall aspect. The rash was taken as an allergic reaction. Within a few days, the erythematous lesions were replaced by hypomelanotic patches, seemingly on the sites of the preceeding exanthema.

On clinical examination, the patient was mildly overweigh and apparently in good health. Several round to oval, non-scaling, slightly raised and well-demarcated hypochromic papules were scattered over the trunk, abdomen, dorsum, and arms (Figure 1). At times, lesions were confluent, giving an overall reticulate pattern. There was no ulceration or alopecia. The palms, soles, and mucous membranes were spared. He was offered a first-generation antihistamine, without relief.

The patient was on antiretroviral therapy for over two decades. His current regimen was lamivudine, tenofovir, atazanavir, and ritonavir. The CD4 cell count was 151 cells/ $\mathrm{mm}^{3}$ and the plasma HIV viral load was 2,378 copies $/ \mathrm{mL}$. An HIV genotyping study was performed to investigate the presence of mutations associated with reduced susceptibility to HIV reverse transcriptase and protease inhibitors. The only mutation of this type was found in the reverse transcriptase codon 70, which probably emerged due to the prior use of zidovudine. The genotypic pattern was suggestive of non-adherence to treatment.

There was no serologic evidence of hepatitis B or hepatitis $\mathrm{C}$ infection. Previous routine non-treponemal tests had been negative for syphilis, but novel studies yielded positive results. The Venereal Disease Research Laboratory (VDRL) titer was positive at a titer of $1 / 2,048$. On further history taking, the patient could not recall having had any prior chancre, but was sexually active and engaged in unprotected sex. Skin lesions slowly regressed and the hypochromic areas repigmented a few weeks after two consecutive weekly administrations of 2.4 million units of intramuscular benzathine penicillin G (Figure 2). No Jarisch-Herxheimer reaction occurred. A clinical diagnosis of secondary syphilis and LS was made. A biopsy was not performed.
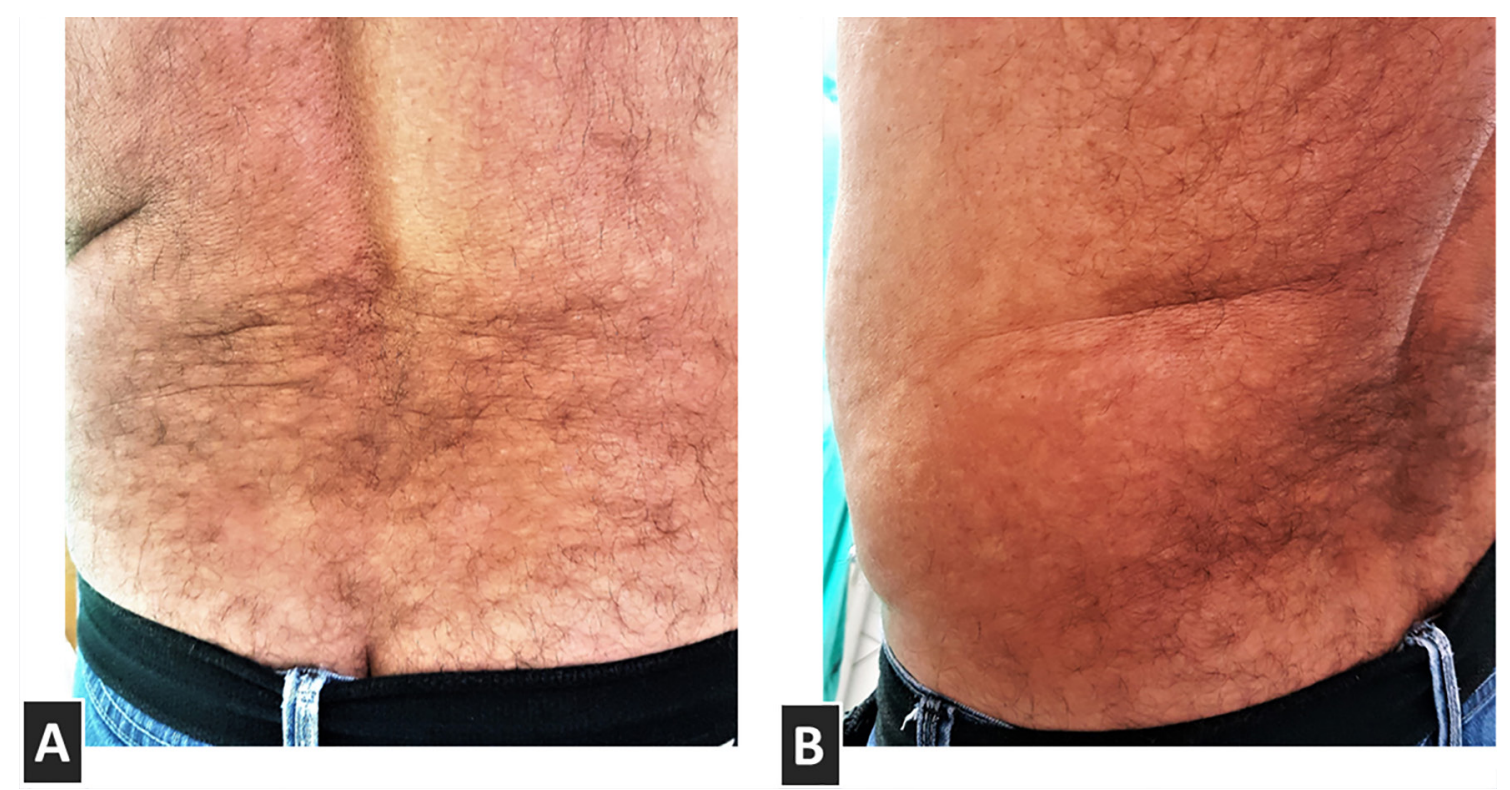

Figure 1 - Dorsal (A) and dorsolateral (B) clinical images of the patient before penicillin treatment. Several round to oval, non-scaling, slightly raised and well-demarcated hypochromic lesions scattered over the trunk, abdomen, and dorsum 


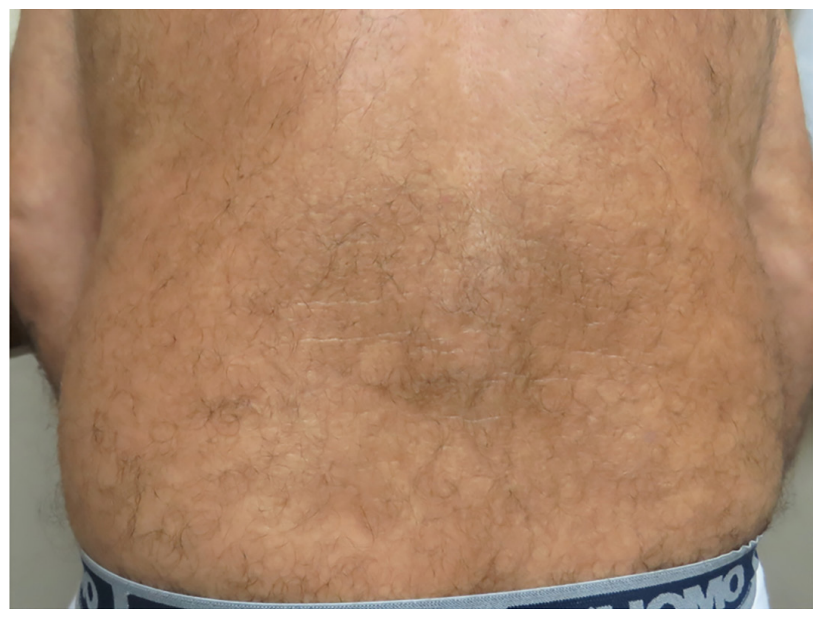

Figure 2 - Almost complete repigmentation a few weeks after treatment

\section{DISCUSSION}

Secondary syphilis is highly heterogeneous and patients may present with a myriad of mucocutaneous manifestations. LS, also known as syphilide pigmentaire, syphilide maculouse du cou, leucoderma colli, leucopathie syphilitique, syphiloderma pigmentosum, syphilitic vitiligo, and vitiligo acquisita syphilitica, is a manifestation of secondary syphilis that is currently rarely reported. LS should not be confused with lues maligna or other atypical presentations of syphilis that have reemerged since the advent of the HIV epidemic. Careful study of the clinical features of the reported cases of LS reveals a diversity of presentations. It is unclear whether the reported cases represent the same or different clinical entities of syphilisrelated pigmentary changes.

Some authors have previously and consistently remarked that LS was usually confined to a limited portion of the skin and that the cervical region, mainly its lateral aspect, was by far the preferred site ${ }^{1-9}$. The occurrence of LS at other sites, such as the trunk, flank, face and extremities, was, however, well-recognized $d^{3,5-7,10,11}$. In sharp contrast, current reports of LS have never mentioned the cervical region. The dyschromic rash favors the upper extremities and hands ${ }^{12-14,16}$, genitals ${ }^{14-17}$, and trunk ${ }^{13,16,18}$.

According to the original description by Hardy ${ }^{1}$, the light areas of syphilide pigmentaire actually correspond to normal skin. He pointed out that there was an abnormal grayish hyperpigmentation, in an overall mottled pattern, which gave the false impression of inner hypopigmented rounded macules ${ }^{1}$. Fournier ${ }^{6}$ completely agreed with this description and coined the confluent hyperpigmented marbling as mélanodermie syphilitique. Other authors questioned this description. Fox ${ }^{5}$ was convinced that, "in the majority if not all" cases, the circular or oval patches were indeed "abnormally white". That was also the impression of subsequent observers ${ }^{3,7,10,11}$. Taylor ${ }^{3}$, after studying "many cases over a period of many years", was "thoroughly convinced" that syphilis could cause both hypo and hyperpigmented macules in some patients. He called leucoderma syphiliticum the former, and pigmentary syphilide the latter, and an illustrative chromo-lithography accompanies his 1885 article $^{3}$. In fact, subsequent authors provided clear evidence of cases in which both hypo and hyperpigmented lesions could be recorded ${ }^{7,11-13}$.

A major debate that has persisted since the early descriptions is whether LS lesions replace the typical rash of secondary syphilis, as seems to have occurred in our patient, or whether it is primary (d`emblée), in which case the leucodermic rash would appear on a previously normal skin. Fournier advocated for the latter hypothesis and stressed that he himself had witnessed, "in a number of cases", the initial development of syphilide pigmentaire on previously normal skin and without any association with prior eruptive lesions ${ }^{6}$. Older and current observers have described these cases $^{8,16}$. By contrast, other observers recorded that the depigmented areas developed precisely at the corresponding sites of the syphilitic $\operatorname{rash}^{7,10,18}$. A similar pattern seems to emerge from the present case, in which the initial lesions were erythematous. Differently, Pandhi et al. ${ }^{12,13}$ reported the simultaneous emergence of both depigmented macular and erythematous papular (or hyperpigmented) lesions in three patients.

Another point of debate is the preference of LS for the female sex. The older literature remarked that the occurrence of LS in a male patient was unusual ${ }^{6,8}$. In his 1858 dermatology book, Hardy ${ }^{1}$ pointed out that he had never seen a single case in a man. Likewise, Fournier ${ }^{6}$ stressed that syphilide pigmentaire is incomparably more frequent in females. Fox ${ }^{5}$ recognized the preference for the female gender, but questioned Fournier's observations claiming that the eminent French dermatologist's studies were performed largely among women. In sharp contrast with ancient literature, 12 out of 14 cases of LS published since the 1970s were in male patients, including the present one ${ }^{12-18}$.

According to the older literature, LS has been generally considered a late expression of secondary syphilis. The rash rarely disappeared under two years and could be permanent ${ }^{3}$. Available treatments had no effect on its natural history ${ }^{6,7,10}$. Current case descriptions provide evidence of LS as an early presentation of secondary syphilis. It seems to have been the case with our patient. Histopathologic studies may show absence of melanin in the epidermis ${ }^{13}$ and even the presence of treponemes around vessels and inside nerve fibers ${ }^{16}$. Penicillin treatment may result in repigmentation of LS macules within a few weeks ${ }^{12,13,15}$ or months ${ }^{14,17}$. 
In summary, the published cases of LS are highly heterogeneous in presentation. We were unable to find current reports of the so-called collar of Venus, as they have been originally described. The occurrence of pigmentary abnormalities during the course of syphilis should be no surprise, since it is a characteristic feature of other treponemal diseases ${ }^{19}$. As proposed by Pandhi et al. ${ }^{13}$, any unusual vitiliginous lesion may justify a search for a syphilitic etiology. One of their patients had indeed started treatment for vitiligo before the true nature of the disease was recognized. The present case report emphasizes the need for clinicians to have a heightened awareness of the varied and unusual clinical phenotypes of syphilis.

\section{CONFLICT OF INTERESTS}

The authors declare there is no conflict of interests.

\section{INFORMED CONSENT}

Informed consent of the patient was obtained for publication of the case.

\section{FINANCIAL SUPPORT}

None.

\section{REFERENCES}

1. Hardy A. Leçons sur le maladies de la peau professèes a L'Hôpital Saint-Louis par le docteur Hardy. Paris: Adrien Delahaye; 1858.

2. Neisser A. Ueber das leucoderma syphiliticum. Vierteljahresschr Dermatol Syph. 1883;10:491-508.

3. Taylor RW. On the pigmentary syphilide. J Cutan Vener Dis. 1885;3:97-100.
4. Dourmishev LA, Dourmishev AL. Syphilis: uncommon presentations in adults. Clin Dermatol. 2005;23:555-64.

5. Fox H. On the so-called pigmentary syphilid. Am J Med Sci. 1878;April;1-6.

6. Fournier A. Traité de la syphilis. Tome I: période primaire période secondaire. Paris: J. Rueff; 1906.

7. Shelmire B, Calhoun TJ. Leukoderma syphiliticum. JAMA. 1926;86:1428-9.

8. Graham Little EG. Case of leucoderma syphiliticum. Proc R Soc Med. 1911;4 Dermatol Sec:102-3.

9. Hutchinson J. Syphilitic leucoderma and the pigmentary syphilide. Br Med J. 1909;1:85-7.

10. McDonagh JE. Leucoderma syphiliticum. Proc R Soc Med. 1910;3 Dermatol Sect:114.

11. Sutton RL. The dyschromias of syphilis. JAMA. 1916;67:1913-7.

12. Pandhi RK, Bedi TR, Bhutani LK. Leucomelanoderma in early syphilis. Br J Vener Dis. 1975;51:348.

13. Pandhi RK, Bedi TR, Bhutani LK. Leucoderma in early syphilis. Br J Vener Dis. 1977;53:19-22.

14. Fiumara NJ, Cahn T. Leukoderma of secondary syphilis: two case reports. Sex Transm Dis. 1982;9:140-2.

15. Pattman RS. Reversible penile leukoderma in a man with secondary syphilis: a case report. Sex Transm Dis. 1982;9:96-7.

16. Poulsen A, Secher L, Kobayasi T, Weismann K. Treponema pallidum in leukoderma syphiliticum demonstrated by electron microscopy. Acta Derm Venereol. 1988;68:102-6.

17. Miranda MF, Bittencourt MJ, Lopes IC, Cumino SS. Leucoderma syphiliticum: a rare expression of the secondary stage diagnosed by histopathology. An Bras Dermatol. 2010;85:5125.

18. Uprety S, Vinay K, De D, Handa S, Saikia UN. Hypopigmented patches on a young man. Clin Exp Dermatol. 2016;41:100-2.

19. Giacani L, Lukehart SA. The endemic treponematoses. Clin Microbiol Rev. 2014;27:89-115. 